Departamento de Zootecnia Especial e Exterior dos Animais Domésticos Diretor: Dr. Joüo Soares Veiga

\title{
A MARCHA NO CAVALO MANGALARGA $\left(^{*}\right)$
}

\author{
Armando Chieffi \\ Preparador \\ 1 estampa ( 1 figura) e 7 figuras no texto
}

INTRODUÇÃO

Andamentos são os movimentos que determinam a locomoção dos animais.

Os Equinos, de acôrdo com a sucessão dos apoios de seus membros, dissociados ou associados aos pares, executam diversas modalidades de andamentos, enquadrados em três grandes itens: - andamentos naturais, andamentos adquiridos e andamentos artificiais.

São considerados naturais, os que o animal executa por instinto (andamentos instintivos), naturalmente, figurando entre êles o passo, o trote, o galope e a andadura. Esta última modalidade - natural de todos os animais que apresentam evidente dolicomorfismo dos membros e branquimorfismo do tronco, nos quais um andamento em diagonal lhes seria prejudicial, pois os membros poderiam se alcançar, ferindo-se - é considerada adquirida, para o cavalo, por alguns autores.

Os andamentos adquiridos são os executados pelo cavalo após educação e, entre êles poderão ser enquadrados o "flyng trot", o passo relevado, o "rack" dos americanos (andamento presente no American Saddle Horse) e a marcha, no cavalo Mangalarga.

São artificiais os andamentos cadenciados, obtidos mediante longos e pacientes exercícios de adestramento. Assim se consideram o "piaffer", "passage", "passo espanhol", etc., reconhecidos como andamentos de alta escola.

$\mathrm{O}$ estudo em questão não se prende pròpriamente a nenhum dos andamentos mencionados entre os naturais, que já foram por nós estudados à luz da cinematografia, mas a um tipo de locomoção existente em nossos cavalos Mangalarga - a marcha - cujas modalidades consideramos adquiridas. Êsse andar, executado em grande número de variedades ou modalidades, é intermediário entre a andadura (andamento com sucessão de apoios laterais) e o trote (andamento com sucessão de apoios diagonais). Em seu extremo mais próximo à andadura, a marcha nada mais é que uma variedade interrompida dêsse andamento. Foi, aliás, como a interpretamos em trabalho já citado,

(*) Nota prévia apresentada $\mathrm{em} 30$ de Abril de 1943, em sessão da Sociedade Paulista de Medicina Veterinária e publicada no número 10, do Ano XIV, da Revista dos Criadores, de Junho de 1943 . 
feito em colaboração com o Dr. Lafayette Homem de Mello. Em seu extremo mais próximo ao trote, chega a ser confundido com o "trote marchado", como teremos oportunidade de demonstrar.

Justifica êste trabalho, a inexistência de qualquer observação sistemática sobre o andar do cavalo Mangalarga.

Os tratados estrangeiros consultados não se referem à marcha, a menos que seja interpretada - o que já dissemos - como andadura interrompida e, mesmo assim, tivemos oportunidade de esclarecer que do confronto do que dizem os Autores com nossas observações pessoais, verificamos diferentes tipos de andadura interrompida. Enquanto uma coincide com a andadura interrompida descrita por GoUBAUX e BARrIER, e foi por nós observada e filmada em um animal novo; outra não era referida pelos autores consultados e foi a notação da andadura de uma égua Mangalarga. Nesta, embora a fotografia que estampamos, extraida do filme (Est. I - Fig. 1) dê a impressão de uma andadura típica, a seqüência do andamento, verificada pelo exame de cada fase do andar, mostra tratar-se, de uma variedade da marcha, que mais se aproxima da andadura.

Dos autores nacionais, salientamos o trabalho de RocHA LAGÔA, sôbre os andamentos e anatomia morfológica do membro pélvico do cavalo Campolina, que se baseia sôbre assunto semelhante. Êste autor, estudando animais dessa raça e interpretando a pista, subdivide a marcha do cavalo Campolina, chegando a conclusão idêntica à que nós verificamos agora examinando o andar do cavalo Mangalarga à luz da cinematografia, dizendo que aquele andamento "se afasta de mais a mais da andadura e progressivamente se aproxima do trote".

RAmos JARDIM, em seu Exterior e Julgamento dos Equídeos, quando trata dos andamentos, emite a opinião de Paravicini Torres, sobre a marcha.

Não foram poucas as publicações referentes ao andar dêsses animais, feitas pelos criadores, algumas das quais são muito bem elucidativas e interpretadas após longos anos de prática, em que a observação visual constituiu sua base. Outras, contudo, são observações falhas, procurando generalizar opiniões pessoais ou exceções, com prejuizo geral, pelas confusões que estabelecem.

\section{MATERIAL E MÉTODO}

Os animais escolhidos para o estudo do andamento, todos da raça Mangalarga, pertencem, alguns ao Govêrno do Estado, outros a criadores diversos, tendo sido nossa preocupação filmar os que considerávamos bons e ruins, inscritos ou não nos livros genealógicos da Associação 
correspondente. Procuramos, assim, afastar qualquer preferência, embora involuntária, para que os animais pudessem representar a média da população, evitando causas de erros maiores.

Os estudos foram iniciados em 1938, sendo baseados na interpretação de filmes, em câmara lenta, com velocidade de 64 imagens por segundo, que focalizaram animais da raça nacional Mangalarga.

Auxiliaram-nos, na confecção dêsse trabalho os Professores Drs. João Soares Veiga, que atualmente rege a Cadeira da qual somos Auxiliares de Ensino, Paulo de Lima Correa - in memoriam - que facilitou, como então Diretor do Departamento da Produção Animal, a visita às fazendas de criação do Estado, Max de Barros Erhart que, como então Diretor da Faculdade, permitiu facilidades ao nosso serviço, Cap. Bela Wodianer, hipologista, do qual pudemos perceber preciosos conhecimentos, Lafayette Homem de Mello, Djalma Lepage, além de outros colegas e criadores, a todos deixando expressados os nossos melhores agradecimentos.

A primeira parte do estudo do andar, no cavalo Mangalarga, que vem sendo feito no Departamento de Zootecnia Especial e Exterior dos Animais Domésticos da Faculdade, e que ora se publica, tratará ùnicamente da definição do andamento, sua interpretação, notação $\mathrm{e}$ conclusões - tudo de acôrdo com as observações dos filmes, ficando para publicações posteriores os assuntos que dizem respeito ao deslocamento do centro de gravidade, pista, comprimento do passo e velocidade da marcha.

\section{DEFINIÇÃO DA MARCHA}

A marcha é um andamento de transição entre a andadura (locomoção marchada, de apoios em bípedes laterais) e o trote (andamento saltado de apoios em bípedes diagonais), marchado, a 2 ou 4 tempos, lateral ou diagonal de acôrdo com a variedade considerada, a velocidade e com o membro que inicia o passo.

Em nossos cavalos, desde a variedade da marcha mais prôxima à andadura, denominada "marcha pròpriamente dita" ou "marcha legítima”, até as demais modalidades, excluindo o trote marchado, é considerada por nós como um andamento adquirido, e essa opinião a manteremos até que experiências bem conduzidas nos venham demonstrar o contrário. Baseamos êsse nosso ponto de vista sôbre a observação de inúmeros animais que, montados, executavam êsse andar, enquanto que soltos, à vontade, trotavam com perfeição e ritmo, mostrando que o trote é efetivamente um andamento natural do cavalo, e o Mangalarga é um cavalo. Assim, a marcha legítima e tôdas suas modalidades será posta em um animal, desde que convenientemente equitado, sendo grande, senão completa, a influência do cavaleiro, que age, quer 
pelas rédeas e pernas, quer, indiretamente, pela localização posterior de seu corpo sôbre o animal. Não há dúvida, contudo, que animais mal conformados existem, que possuem, por vezes, andar que muito se aproxima da andadura, desgracioso, com uma dissincronização completa de apoios e êsses exemplares não devem merecer nossa atenção, quando se pretende escolher raçadores, merecendo, porém, um estudo científico. Neles se percebe um desequilíbrio evidente, possuem, geralmente, garupa inclinada e maus aprumos.

Outro fato que nos levou à conclusão de que êsse andamento é adquirido, reside na observação feita em filmes que, infelizmente, por uma deficiência de aparelhamento, impediu um exame mais detalhado, mas que permitiu verificar o andamento de animais ainda não mansos de sela, que se locomoveram em trote perfeito, com período de suspensão. O proprietário desses animais tem a firme convicção que seus exemplares darão marcha trotada, o que tambem acreditamos.

Estudos que veem sendo encetados neste Departamento, esperamos, virão comprovar experimentalmente, essa nossa afirmação.

Interpretando a definição, vimos ser a marcha um andamento marchado, pois que, em tôdas as fases consideradas, o animal está sempre em contato com o solo, por um, dois ou três membros. Estes, na maioria das vezes, se apoiam e se elevam na mesma ordem verificada no andamento "passo" e foi por essa razão que dissemos, na definição, ser lateral ou diagonal, de conformidade com o membro que se leva em consideração para o início do passo. Êsse fato ficará melhor evidenciado, quando por ocasião do estudo das notações.

Também a modalidade mais próxima do trote, que, como veremos, chega a ser considerada um "trote marchado", faz variar a característica de andamento lateral, pois desaparece a fase do apôio em membros laterais, persistindo sòmente a diagonal.

O espaço de tempo que separa o apôio de cada membro varia, na marcha, de conformidade com a variedade considerada. Em algumas, sendo os apoios dos membros separados por tempo superior a 0,10 de segundo, ouvem-se 4 batidas distintas e o andamento é a 4 tempos, enquanto que outras vezes só são percebidos os ruidos que fazem o primeiro membro a tocar o solo e o bípede diagonal que segue, passando o andamento a ter dois tempos. As variedades de marcha a 4 tempos são percebidas quando há afastamento entre a queda de um membro anterior e a do posterior oposto em diagonal e isto se verifica sempre que houver apoios laterais acentuados. A conclusão a que então chegamos é de que a marcha legítima ou marcha pròpriamente dita, com apoios laterais evidentes, é freqüentemente a 4 tempos e a medida que nos aproximamos do trote, passa o andamento a ter dois tempos. Foi 
o que observamos em tôdas as anotações examinadas. E', porém, evidente que a marcha, à medida que se aproxima da andadura, com o desaparecimento de fases de apôio tripedal, monopedal e diagonal, o que significa uma tendência à união da queda do membro posterior com o anterior do mesmo lado que lhe segue, tenderá a ter também 2 tempos. Mas neste caso, o andamento deixará de ser marcha, para se localizar na andadura.

Para maior facilidade de exposição, poremos de parte, em nosso trabalho, tôdas as denominações dadas a essa variedade do andamento, por vezes regionais, como: passo, marcha guinilheira, picada, batida de cão, etc., subdividindo-o em dois grandes grupos: marcha pròpriamente dita ou marcha legítima e marcha trotada, continuando a adotar, sob a denominação genérica de marcha, o modo de andar do cavalo Mangalarga em geral.

\section{NOTAÇÃO DA MARCHA}

A representação gráfica de um andamento recebe o nome de notação.

Esta pode representar a pista do andamento, como interpretar as diferentes fases de apôio e suspensão dos membros.

Diversos processos existem para representar gràficamente a locomoção do cavalo. Para tornar possível a compreensão dos métodos adotados neste trabalho, na notação da marcha, descreveremos os que serão usados, como os processos de Marey e o de Smith.

Pelo método de Marey a notação é feita em duas linhas horizontais e paralelas, sôbre as quais são representados os apoios dos membros. Convencionou-se que, abaixo de cada traço horizontal, seriam representados, em claro, os membros direitos e acima e em escuro ou traços, os esquerdos. O comprimento dos traços claros e escuros é proporcional à duração do apôio do membro correspondente.

$\mathrm{O}$ método adotado por Smith consiste em representações esquemáticas do corpo do cavalo visto pela face superior, nas quais a parte mais estreita corresponderia à cabeça e em cujo interior, os membros em apôio são presentes por pontos.

No processo de Marey, em nosso trabalho, os algarismos romanos, no interior das figuras, indicam o número de membros em apôio; os arábicos revelam, em fração de 1/64 de segundo (velocidade do filme), a duração dos períodos de apôio e suspensão dos membros. Abaixo das figuras representamos as batidas, os tempos decorridos entre as diversas fases e o comprimento do passo completo.

Dos 54 animais filmados, que foram cuidadosamente examinados e estudados, retiramos 24 notações, que são as que possuíamos com 
comprimento do passo completo, e que foram fichadas. Sôbre elas nos baseamos para apresentar o quadro de apôio confeccionado e escolhemos para estampar as notações extremas da marcha, além de outras que possuem seqüência de apôio diversa da que se nota normalmente.

NOTAÇÕES EXTREMAS DA MARCHA

A) - Nome do animal: - Lanterna.

Andamento: - Marcha legítima ou marcha pròpriamente dita.
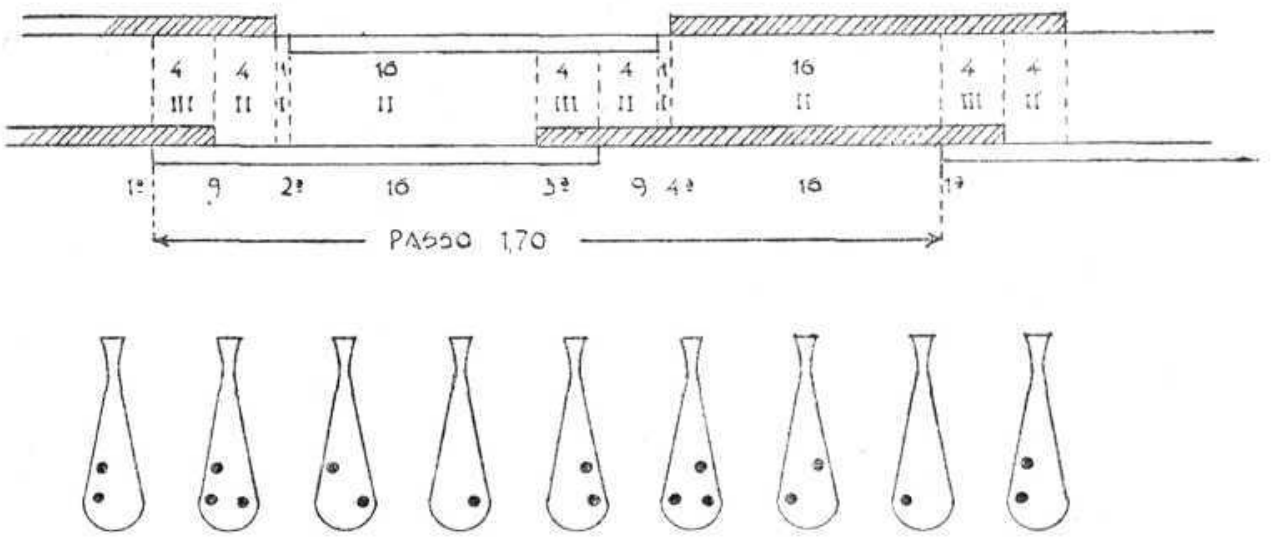

Fig. 2

Interpretação: - a) Notam-se apoios tripedal anterior esquerdo (4/64") ; diagonal esquerdo (4/64") ; monopedal posterior direito (1/64") ; lateral direito $(16 / 64 ")$; tripedal anterior direito (4/64") ; diagonal direito (4/64") ; monopedal posterior esquerdo $(1 / 64$ ") ; lateral esquerdo (16/64") e novamente tripedal anterior esquerdo ;

b) Predominância dos apoios laterais sôbre os diagonais, permanecendo os primeiros 16/64" em um passo de 50/64";

c) Entre cada apôio lateral há um diagonal, um tripedal anterior e um monopedal posterior;

d) Os membros posteriores permaneceram maior tempo em apôio (29/64") que os anteriores (24/64") ;

e) Se a primeira batida for considerada ao se por o posterior direito no solo, seguem-se o anterior direito, após $0,14 "$; o posterior esquerdo, após 0,25 "; o anterior esquerdo, após 0,14 ", terminando o passo com a nova batida do posterior direito.

Nessa notação vê-se o que referimos, na definição, quando dissemos ser a marcha um andamento lateral ou diagonal, em algumas 
variedades, de conformidade com o membro que inicia o passo. Se êsse membro for um anterior, segue-se o posterior oposto em diagonal.

f) E' um andamento a 4 tempos, pois são ouvidas 4 batidas, correspondentes ao apôio de cada membro no solo. Isto se verifica já que entre o primeiro e segundo apôio há um espaço de tempo de 0,14 ", o que permite ouvir dois sons distintos e entre o segundo e terceiro apôio, um espaço de 0,25 ". As quatro batidas são, assim, distintas, se bem que aproximadas duas a duas.

\section{QUADRO DE APÔIO DE 24 NOTAÇÕES EXTRAIDAS DE FILMES DO ANDAR DE CAVALOS MANGALARGA}

\begin{tabular}{|c|c|c|c|c|c|c|c|c|c|}
\hline & Andamento & $\begin{array}{l}\text { Tripedal } \\
\text { ant. esq. }\end{array}$ & $\begin{array}{l}\text { Bipedal } \\
\text { diag. } \\
\text { esq. }\end{array}$ & $\begin{array}{l}\text { Monop. } \\
\text { post. } \\
\text { dir. }\end{array}$ & $\begin{array}{l}\text { Bipedal } \\
\text { lat. dir. }\end{array}$ & $\begin{array}{l}\text { Tripedal } \\
\text { ant } \text { dir. }\end{array}$ & $\begin{array}{l}\text { Bipedal } \\
\text { diag. } \\
\text { dir. }\end{array}$ & $\begin{array}{l}\text { Monop. } \\
\text { post. } \\
\text { esq. }\end{array}$ & $\begin{array}{c}\text { Bipedal } \\
\text { lat. esq. }\end{array}$ \\
\hline 1 & M. & 4 & 4 & 1 & 16 & 4 & 4 & 1 & 16 \\
\hline 2 & M. & 4 & 5 & - & 16 & 4 & 5 & - & 16 \\
\hline 3 & M. & 3 & 5 & 2 & 12 & 3 & 5 & 2 & 12 \\
\hline 4 & M. & 3 & 8 & 2 & 9 & 3 & 8 & 2 & 9 \\
\hline 5 & M. & 3 & 7 & 3 & 7 & 3 & 7 & 3 & 7 \\
\hline 6 & M. & 2 & 8 & 1 & 7 & 2 & 8 & 1 & 7 \\
\hline 7 & M. T. & - & 12 & 2 & 8 & - & 12 & 2 & 8 \\
\hline 8 & M. T. & 3 & 9 & 2 & 4 & 3 & 9 & 2 & 4 \\
\hline 9 & M. T: & 2 & 13 & 2 & 5 & 2 & 13 & 2 & 5 \\
\hline 10 & M. T. & 4 & 14 & 2 & 5 & 4 & 14 & 2 & 5 \\
\hline 11 & M. T. & 2 & 17 & - & 5 & 2 & 17 & - & 5 \\
\hline 12 & M. T. & - & 16 & 2 & 4 & - & 16 & 2 & 4 \\
\hline 13 & M. T. & - & 18 & - & 4 & - & 18 & - & 4 \\
\hline 14 & M. T. & 2 & 11 & 3 & 3 & 2 & 11 & 3 & 3 \\
\hline 15 & M. T. & 1 & 14 & 2 & 3 & 1 & 14 & 2 & 3 \\
\hline 16 & M. T. & 2 & 15 & 1 & 3 & 2 & 15 & 1 & 3 \\
\hline 17 & M. T. & 1 & 17 & 1 & 3 & 1 & 17 & 1 & 3 \\
\hline 18 & M. T. & - & 18 & 2 & 3 & - & 18 & 2 & 3 \\
\hline 19 & M. T. & 2 & 18 & 2 & 3 & 2 & 18 & 2 & 3 \\
\hline 20 & M. T. & 3 & 15 & 1 & 2 & 3 & 15 & 1 & 2 \\
\hline 21 & M. T. & 2 & 18 & - & - & 2 & 18 & - & - \\
\hline 22 & M. T. & 2 & 19 & - & - & 2 & 19 & - & - \\
\hline 23 & M. T. & 1 & 19. & 3 & - & 1 & 19 & 3 & - \\
\hline 24 & M. T. & - & 23 & - & - & - & 23 & - & - \\
\hline
\end{tabular}

NOTA: - Os números representam frações de sessenta e quatro avos de segundo (velocidade do filme). 
B) - Nome do animal: - Bastilha.

Andamento: - Marcha trotada.
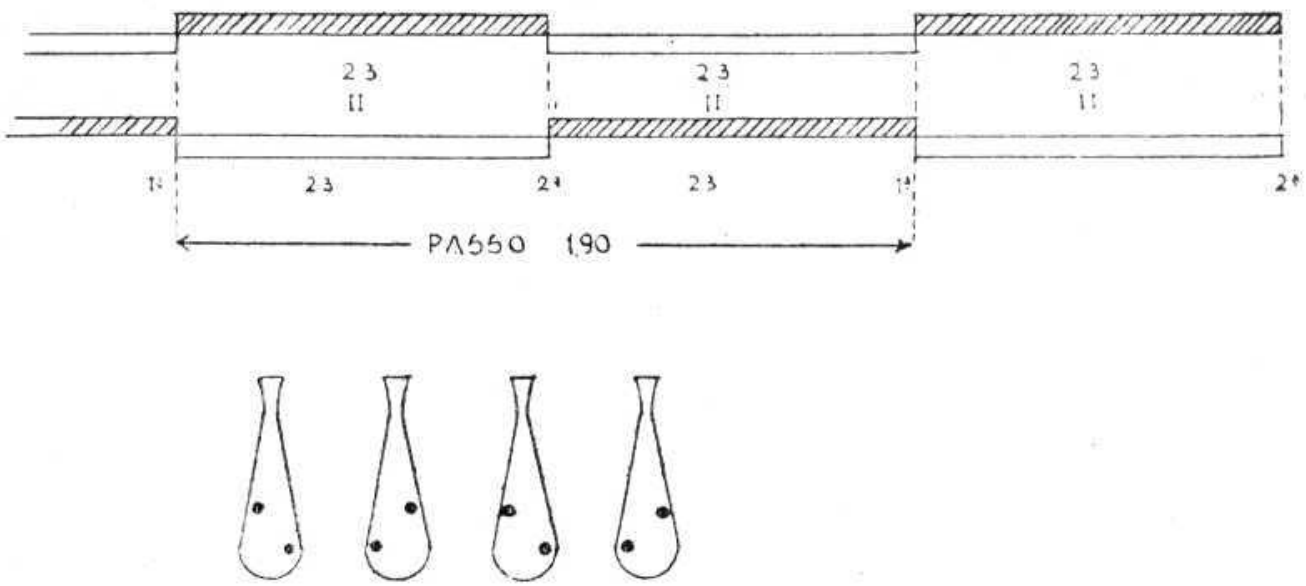

Fig. 3

Interpretação: - a) Há apoios diagonais que se sucedem sem interrupção. A filmagem, na velocidade de 64 imagens por segundo, não permitiu a observação de dissociações dos membros em diagonal, que caem e se elevam ao mesmo tempo. Não há dúvida, porém, que uma maior velocidade do film poderá mostrar tais dissociações.

b) Os apoios bipedais diagonais têm duração de 23/64", em um passo de $46 / 64$ ".

c) Ouvem-se duas batidas em cada passo, separadas por um espaço de tempo de quase 0,36 ".

d) Essa notação é idêntica à do trote marchado, modalidade de andamento natural e lento dos cavalos, que às vezes se diferencia da que representamos ùnicamente pelo fato de haver sucessão de apoios diagonais intercalados por períodos com base quadrupedal. Esta fase quadrupedal do trote marchado foi por nós demonstrada em trabalho já publicado, na Revista de Indústria Animal, quando estudamos o trote do cavalo pela cinematografia. 
NOTAÇÖES INTERMEDIARIAS AOS DOIS EXTREMOS COM

SUCESSÕES DE APOIOS DIVERSAS DAS QUE

NORMALMENTE SE ENCONTRAM

C) - Nome do animal: - Draga.

Andamento: - Marcha trotada.
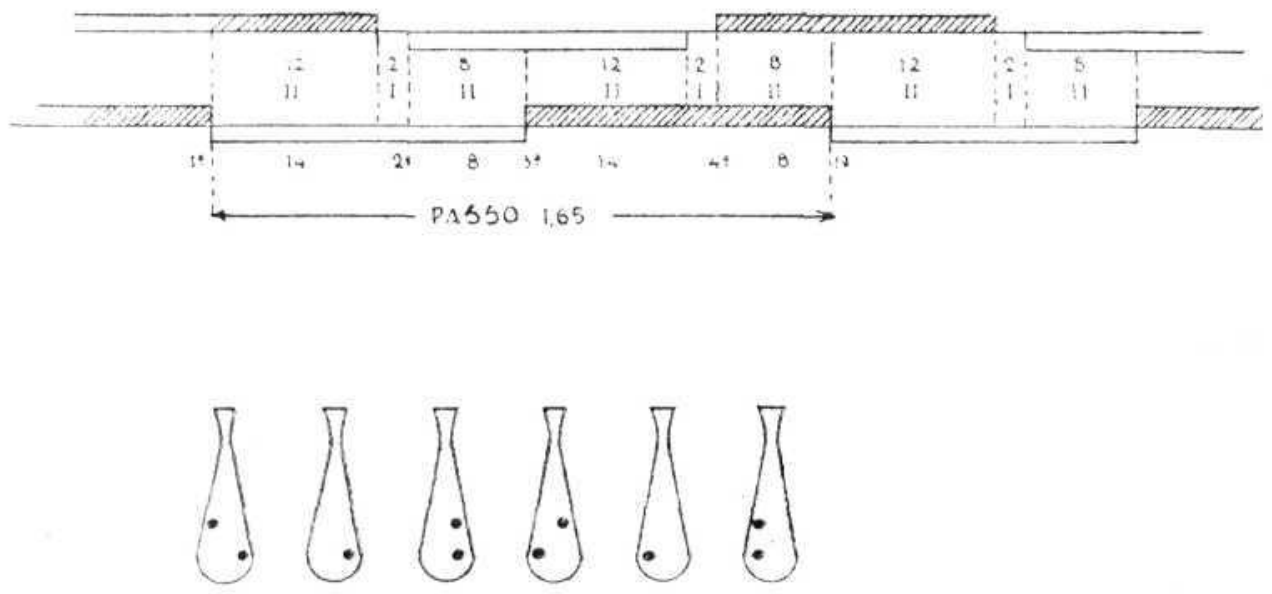

Fig. 4

In t e r p r e t a çã o : - a) Apoios bipedal diagonal esquerdo $(12 / 64 ")$; monopedal posterior direito (2/64") ; bipedal lateral direito (8/64") ; bipedal diagonal direito (12/64") ; monopedal posterior esquerdo (2/64"); bipedal lateral esquerdo (8/64"), terminando o passo.

b) Predominância dos apoios diagonais sôbre os laterais, fato que determina a modalidade de marcha trotada, permanecendo os primeiros $12 / 64$ " num passo de $44 / 64$ ".

c) Entre cada apôio diagonal, nota-se, um monopedal e outro lateral.

d) O desaparecimento do apôio tripedal se deve ao fato de um membro posterior permanecer no solo, elevando-se na mesma ocasião de outro tocar, enquanto que, no caso da existência da base tripedal, um se eleva depois do outro tocar o solo e permanecer determinado espaço de tempo em apôio.

e) Os membros posteriores ficam maior tempo em contato com o solo (22/64") que os anteriores $(20 / 64)$, o que aliás é uma diferença insignificante.

f) Sendo a primeira batida considerada ao se por o membro posterior direito no solo, a outra se verifica com o cair do anterior direito, após, 0,21", seguindo-se a queda do posterior esquerdo, depois 
de 0,12 " e a quarta, depois de 0,21 ", com o apôio do membro anterior esquerdo.

g) O andamento é também a 4 tempos, ouvindo-se 4 batidas aproximadas duas a duas, havendo uma tendência das batidas entre o segundo e terceiro membros se confundirem. Aliás isto se verifica a medida que a marcha trotada é mais acentuada, notando-se então um menor espaço de tempo entre a queda de um membro anterior e a do posterior oposto em diagonal. A medida que êsse espaço aumenta, cairemos na marcha legítima, com maior separação entre as batidas do segundo e terceiro membros, tornando cada vez mais perceptível os quatro sons que caracterizam um andamento a quatro tempos.

D) - Nome do animal: - Dante.

Andamento: - Marcha trotada.
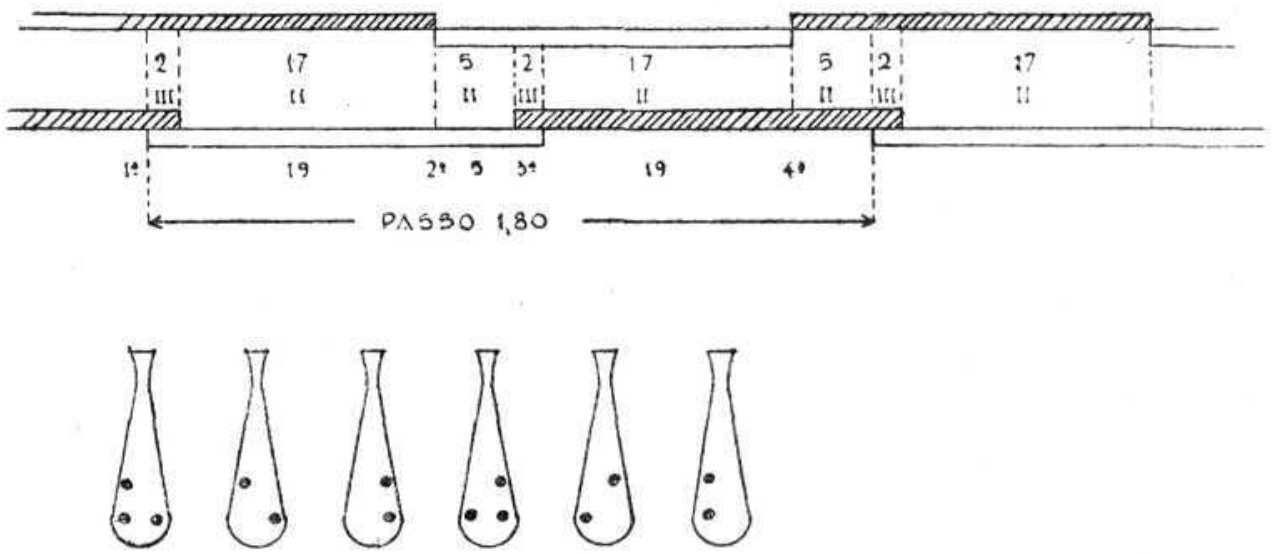

Fig. 5

In terpretação: - a) A sequência de apôio faz notar a inexistência da base monopedal posterior, devido ao fato dos membros anteriores anteciparem sua queda, ou retardarem sua suspensão, o que vem determinar o mesmo fenômeno. Dêste modo, imediatamente após uma base de apôio bipedal diagonal, segue-se a lateral, e entre esta e a nova fase diagonal, há uma tripedal anterior que dura $2 / 64$ ".

b) Entre a segunda e terceira batida isto é, entre o apôio de um membro anterior e a queda de um posterior oposto em diagonal, há um espaço de tempo de 5/64", ou sejam, 0,08 ", insuficiente para permitir ao nosso ouvido dois sons distintos. Êste fato faz com que o anda- 
mento dêsse tipo seja executado em dois tempos, ouvindo-se duas batidas longas.

c) Quanto ao mais, e levando em consideração as variações assinaladas na notação, verificam-se as mesmas particularidades já referidas em outras modalidades.

E) - Nome do animal: - Cravo.

Andamento: - Marcha trotada.
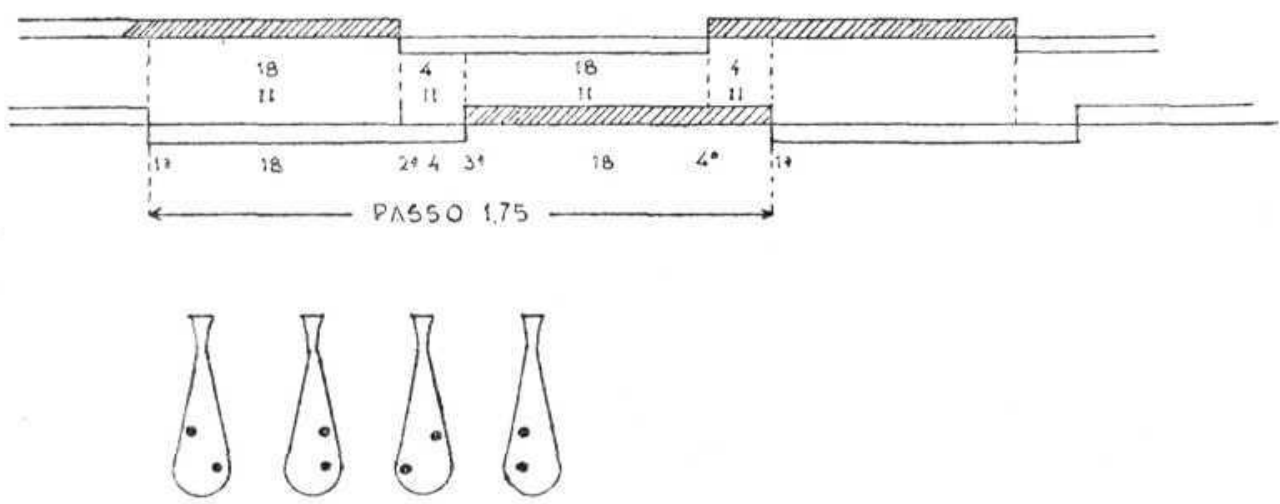

Fig. 6

Interpretação: - a) Nesta notação sòmente permanecem duas fases de apôio: uma bipedal diagonal e outra bipedal lateral, que se sucedem em intervalos regulares. As fases diagonais predominam francamente sôbre as laterais, visto como, em um passo de $44 / 64$ ", os diagonais permanecem 18/64" e os laterais 4/64".

b) O sincronismo entre a queda e suspensão dos membros anteriores e posteriores faz desaparecer os apoios tripedais e monopedais, tendendo o andamento, com a diminuição da fase lateral e aumento da diagonal, a um trote normal.

c) Entre a segunda e terceira batidas, determinadas pela queda do membro anterior direito e posterior oposto em diagonal, por exemplo, há um espaço de tempo de 4/64", ou sejam, 0,06", fazendo com que, também para êste caso, aja fusão entre as batidas e o andamento se torna a dois tempos. 
F) - Nome do animal: - Salamanca.

Andamento: - Marcha trotada.
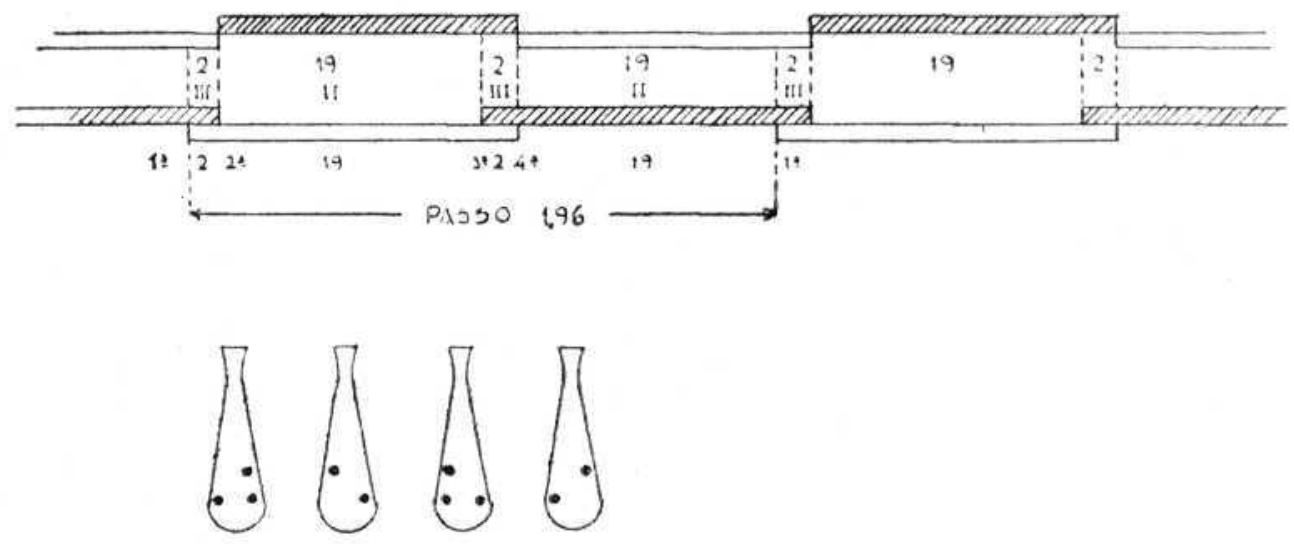

Fig. 7

In ter pretação : - a) As duas fazes de apôio diagonal, verificadas em cada passo, longas, de duração de 19/64" em um passo de 42/64", são separadas por fases de sustentação tripedais anteriores, que permanecem $2 / 64$ ".

b) Na maioria das notações, vimos que à queda de um membro posterior seguia-se a de um anterior do mesmo lado e depois dêste tomar apôio, seria verificada a queda do posterior em diagonal. Isto não se verifica na notação da Figura 7. As fases não se sucedem com a seqüência normalmente anotada.

$\mathrm{O}$ que percebemos de início, é que, contràriamente aos demais tipos, os membros anteriores não se antecipam aos posteriores no apôio. São os posteriores que tocam o solo antecipadamente, de modo a inverter a ordem referida. Assim, após a queda do membro posterior direito, segue-se o anterior oposto em diagonal (anterior esquerdo) e depois o posterior esquerdo, seguido pelo anterior direito. Vemos, então que os membros anteriores, direito ou esquerdo, caem no solo antes dos posteriores, direito ou esquerdo.

c) O sincronismo dos apoios e suspensão dos membros anteriores impede a formação da base de apôio monopedal vista em outras notações e esta, mesma que presente, estaria localizada, no caso em estudo, após um apôio tripedal, enquanto que nas notações já referidas, o apôio monopedal segue a fase de apôio bipedal diagonal.

d) O andamento é a dois tempos, pois há fusão das batidas referentes à queda do membro posterior e anterior oposto em diagonal, separadas apenas por $2 / 64$ ". 
G) - Nome do animal: - Cravo.

Andamento: - Marcha trotada.
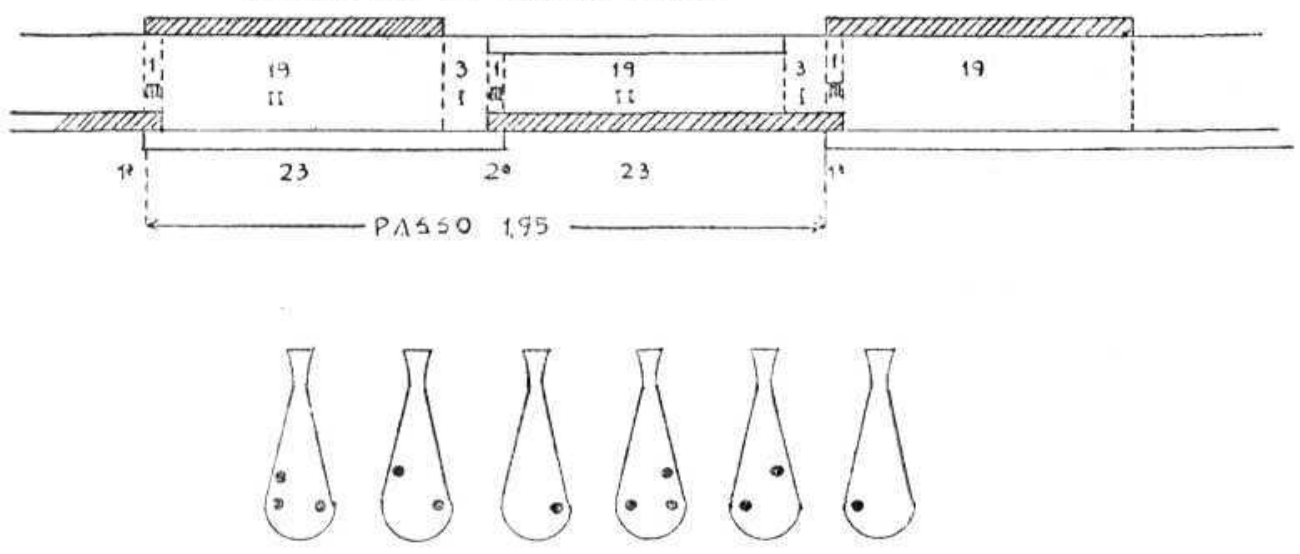

Fig. 8

In terpretação: - a) As fases bipedais diagonais são longas (19/64" em um passo de $46 / 64$ "), separadas por duas bases : uma monopedal posterior (3/64") outro tripedal anterior (1/64"). Nāo há o apôio lateral que normalmente se verifica entre as sustentações monopedais e tripedais. O desaparecimento dessa fase lateral é devido aos membros anteriores fazerem seu apôio sempre ao mesmo tempo que os posteriores em diagonal, tal como em um trote normal. A fase de suspensão dos membros, porém, não se verifica também ao mesmo tempo, elevando-se os anteriores inicialmente, e os posteriores depois de 4/64". Nas demais notações, como vimos, os anteriores normalmente se antecipam aos posteriores opostos em diagonal, tanto em sua fase de apôio como na suspensão.

b) Os membros anteriores permanecem menos tempo no solo e a observação dêsse andar chama atenção pelo levantar rápido e evidente das mãos.

c) E' um andamento a dois tempos, como no trote normal, desde que a queda dos membros se verifica sempre ao mesmo tempo e as batidas dos membros anteriores e posteriores se confundem.

\section{CONCLUSÕES SÔBRE O EXAME DAS NOTACÕES}

A primeira dessas notações (Fig. 2), que se refere à marcha pròpriamente dita, com seqüências de apoio tripedais anteriores, bipedais diagonais, monopedais posteriores, bipedais laterais, etc., é a que se nota freqüentemente, mesmo na marcha trotada e, nos 24 casos fichados, para só documentar com os dados que se encontram arquivados, aparece 14 vezes, como se verifica pelo quadro de apôio apresentado. 
Esta seqüência desaparecerá, a medida que a marcha trotada se acentua, isto é, que tende a diminuir o apôio lateral, com franca predominância do diagonal.

A principal diferenciação entre as notações mais freqüentes, com as bases de apôio referidas, reside no tempo de permanência de cada fase, às vezes com predominância da sustentação lateral sôbre a diagonal (como nos casos 1, 3, 4, 5 e 6), na marcha pròpriamente dita, às vezes com ligeira ou visível predominância dos apoios diagonais sôbre os laterais (como nos casos 8, 9, 10,14, 15, 16, 17, 19 e 20), quando na marcha trotada.

Afora essa seqüência notamos, nos andamentos fichados e que resumimos no quadro de apôio:

a) Três casos $(7,12$ e 18), em que desaparece o apôio tripedal anterior, residindo a variação, entre os três casos, no tempo de permanência dos membros no solo. A descrição da notação consta da Fig. 4;

b) Um caso de inexistência de apôio monopedal posterior (11 - Fig. 5) ;

c) Um caso de inexistência de apôio tripedal anterior e monopedal posterior, existindo, portanto, duas únicas fases de apôio; diagonal e lateral (13 - Fig. 6);

d) Dois casos de inexistência de apoios bipedais laterais e monopedais posteriores (21 e $22-$ Fig. 7 ) ;

e) Um caso de inexistencia de apôio bipedal lateral, com a presença de grandes apoios diagonais, intercalados por fases monopedais posteriores e tripedais anteriores (23 - Fig. 8);

f) Um caso de inexistência de apôio bipedal lateral, com persistência dos diagonais que se sucedem sem outra base de sustentação (24 - Fig. 3).

Devemos notar que o andar representado na Fig. 8 é o do mesmo animal que determinou a notação focalizada na Fig. 6 e nesta vemos que os membros se dissociaram ao se por no solo. associando-se ao se elevar. Êste fato é o oposto do que se verifica na Fig. 8. A velocidade do andamento no caso da Fig. 8 foi maior, e as bases de apôio ficaram alteradas. Com efeito, enquanto na Fig. 6 não houve apoios tripedais e nem monopedais, na Fig. 8 ambas essas sustentações aparecem, faltando a lateral.

Isto nos faz pensar que a marcha, dentro dos apoios que consideramos possiveis de aparecer, conforme a seqüência apontada, tem suas bases alteradas, de conformidade com a velocidade do andamento, ainda que seja considerada em um mesmo animal. Este fato, contudo, complica o perfeito conhecimento da matéria, para a qual tivemos o ensejo de contribuir, com a apresentação deste trabalho. 
As nossas observações, porém, - devemos confessar, - longe estão de elucidar perfeitamente o assunto, constituindo apenas uma tentativa que servirá para posteriores estudos, visando o conhecimento exato do andar do cavalo Mangalarga.

\section{BIBLIOGRAFIA}

Chieffi, A. - Homem de Mello, L. - 1939 - Contribuição para o estudo da localização do centro de gravidade no corpo dos animais domésticos e dos fatores que produzem seu deslocamento temporário ou permanente. I: Deslocamento do centro de gravidade nas atitudes, nos movimentos sôbre o lugar, nos andamentos e nos saltos do cavalo. Rev. Fac. Med. Vet., São Paulo, 1 (2) : 97-152.

Chiefri, A. - 1940 - Contribuição para o estudo da localização do centro de gravidade no corpo dos animais domésticos e dos fatores que produzem seu deslocamento temporário ou permanente. II: Estudo do trote do cavalo pela cinematografia. Rev. Ind. Animal, 3 N.S. (1) : 116-25.

Goubaux, A. - Barrier, G. - 1890 - L'Exterieur du cheval. Paris, Asselin et Cie.

HAYES, M. H. - 1930 - Points of the horse (A treatise on the conformation, movements, breeds and evolution of the horse) 5th. ed. London, Hurst \& Blackett Limited.

Lesbre, F. X. - 1930 - Précis d'Extérieur du cheval et des principaux mammifères domestiques. 3ème. ed. Paris, Vigot frères.

Marq, J. - Lahaye, J. - 1934 - Extérieur du cheval. Gembloux, Jules Duculot.

Nogueira, O. R. - 1920 - Exterior dos grandes animais domesticos. São Paulo, Typ. Sociedade Editora Olegario Ribeiro.

Plumb, C. S. - 1928 - Judging farm animals. New York, Orange Judd Publishing Company, Inc.

RAMos JARDIM, W. - 1940 - Exterior e julgamento dos equideos. Piracicaba, Tip. Aloisi.

Rocha LAGÔA, T. - 1928 - Dos andamentos e da anatomia morphologica do membro pelvico do cavalo Campolina. Tése. Rio de Janeiro.

Smith, F. - 1921 - A manual of veterinary Physiology. 5th. ed. London, Baillière, Tindall \& Cox.

Zwaenepoel, H. - 1926 - Préeis du cours d'extérieur du cheval. 2ème. ed. Bruxelles, G. Bothy. 


\section{EXPLICAÇÃO DA FIGURA 1}

Fotografia extraída de filme, que dá impressão de uma andadura típica, a sequência do andamento, mostra todavia tratar-se, de uma variedade de marcha. 
Armando Chieffi,

A marcha no cavalo Mangalarga
Rev. Fac, Med. Vet. S. Faudo, Vol, 2. fase. 3 Estampa 1

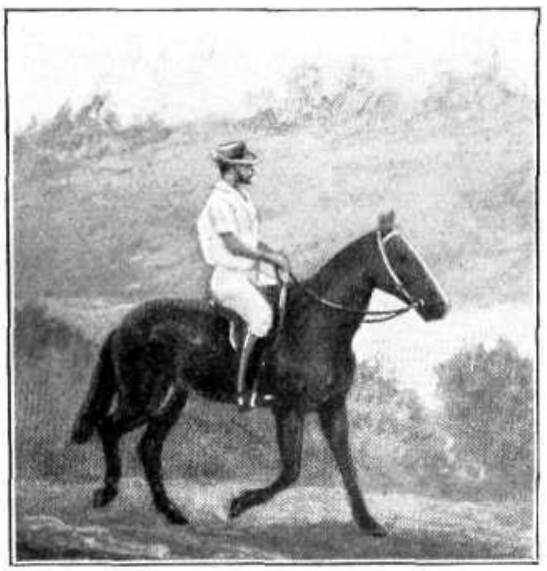

